\title{
A handful of Nobels
}

\author{
Five laureates from the 2012 Lindau Nobel Laureate Meeting give us their thoughts on \\ everything from the Higgs boson to climate change.
}

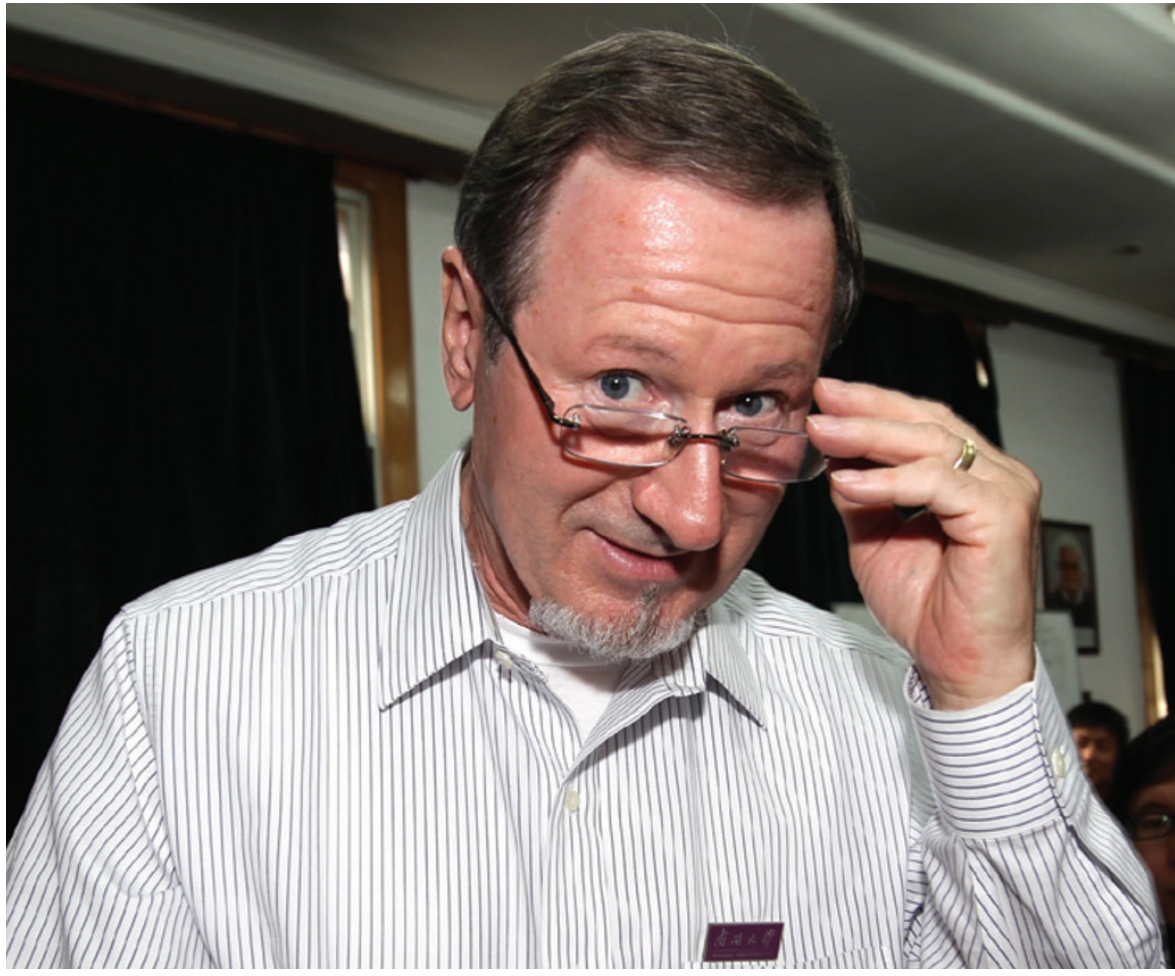

\section{Q\&A DOUGLAS OSHEROFF \\ Finding fascination in nature}

Douglas Osheroff is a Stanford University physicist focused on ultralow-temperature physics of quantum fluids and solids. Co-recipient of the 1996 Nobel Prize in Physics for the discovery of superfluidity in helium-3, Osheroff spent much of his childhood performing science experiments - often with an element of danger - that helped hone his technical skills.

You were interested in natural sciences from an early age. What triggered this? I was six when I got an electric train for Christmas. My parents took a nap in the middle of the afternoon; by the time their nap was over I had completely disassembled the locomotive to get the electric motor out. I don't know what made me do that!

From age five to when I graduated from high school, I was fascinated by electricity and magnetism. A lot of the stuff I did was dangerous, although my parents didn't reprimand me or try to force me into safer activities. I think that my father was actually intrigued by my fascination with things electrical.
Later, my high-school chemistry teacher spelled out the way he thought about research. He said that when you do research you ask questions of nature. That idea has always fascinated me, and in fact describes the way I approach research. Every time you do an experiment you are asking a question or a series of questions of nature, and nature then has to answer them - but nature's answers are complicated, so you have to ask more questions.

Did you have any mentors, and how did they shape your academic development? My father had a lot to do with developing my interest in science. Other than that, Richard Feynman had an impact on me.
In my freshman class, everyone at Caltech (California Institute of Technology) had to take two years of Feynman physics. For people like me who were absorbed by nature, that was phenomenal, because he took his fascination and combined it with mathematical understanding in a way that made physics a more interesting and more powerful science.

How did you become interested in lowtemperature physics and helium-3? My interest with low temperatures came about in primary (elementary) school when I started freezing mercury. Our class would go on picnics and my mother would always provide frozen desserts that were packed in dry ice. At the time, I also had a lot of mercury that I had taken out from used batteries collected from drugstores around town. When I put the mercury on this dry ice it froze, it became a solid. I was fascinated.

But my interest really peaked when I was doing graduate work at Cornell University at the end of the 1960s. There were two talks during the first semester that I attended on new refrigeration devices that had been developed very recently. I recognized that these new refrigeration technologies would allow me to look at nature in a different way, and see things that no one had ever seen before.

One was the helium-3-helium-4 dilution refrigerator - in fact I built one in my first year of grad school. The other was Pomeranchuk cooling, which is a very strange thing. If you take liquid helium-3 at sufficiently low temperatures, just above absolute zero, and you compress it under a pressure of 34 atmospheres, you start converting the liquid to solid. For every

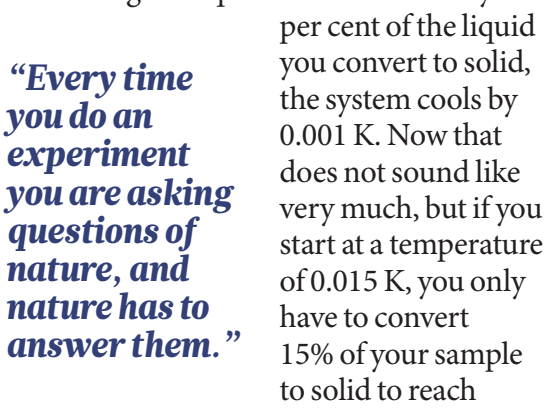

absolute zero. Of course, you don't reach absolute zero, but you can get pretty close. When I heard the talk on Pomeranchuk 
cooling, I said: "I have to have one of these things." So I started building a

Pomeranchuk refrigerator.

I didn't know what was likely to happen at temperatures this close to absolute zero. When I was testing my Pomeranchuk cooling device, all of a sudden I saw a sharp decrease in the rate of cooling. I was unhappy to see this and, at first, I tried to resume the original rate of cooling. But ultimately I found that this decrease was a signature of some highly reproducible phase transition in the mixture of liquid and solid helium-3. It took me a while to understand, but the signature was due to a jump in the heat capacity as the liquid became a superfluid. To this day (even right now as I tell you the story), the hair stands up on the back of my neck because I remember the excitement when I realized what I had discovered.

:3 What are the key elements leading to the successful conception and execution of Nobel-prizewinning research? If you're an experimentalist, you have to know how to design and build things, and understand what's going to work and what won't. At the same time you need to have a deep curiosity about the behaviour of matter and its limits - in my case at the limit of very low temperatures. And then you need to have a good understanding of what you expect to see, because what is probably most important is seeing something that you didn't expect - and you cannot know what that is unless you know what you expect in the first place. Of course, there is another side to this - when 풀 you clearly don't know what to expect, but are able to realize the importance of your unexpected findings, as was the case with Arno Penzias and Robert Wilson in their discovery of cosmic background radiation.

You (and Penzias and Wilson) did groundbreaking research while at Bell Labs during its golden era. What were the key ingredients for Bell Labs' research successes, and do you think that similar research environments exist or could be created today?

Things have changed a lot. Bell Labs is a very different place than when I was there. Then it was a very big and complicated organization. I was in Area 10, and we were allowed to research whatever we wanted. The basic research part of Bell Labs was supported by funds that (parent company) AT\&T got from the regional operating companies. Once the Bell System was broken up in the 1980s, that funding disappeared. I think that was the beginning of the end of fundamental scientific research at Bell Labs, although applied research continued.

It's almost impossible to create a similar

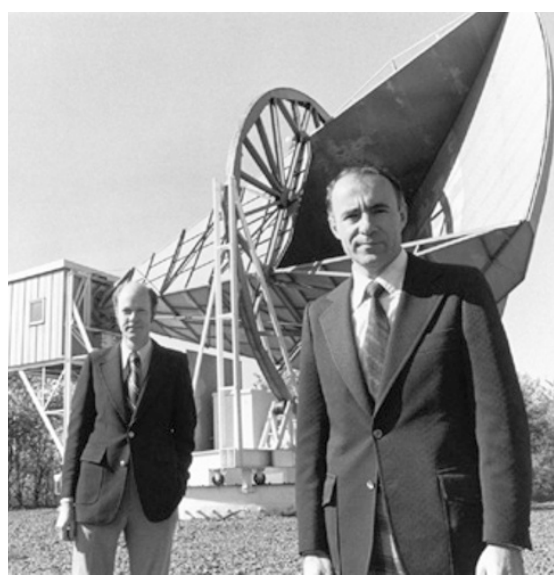

Bell Labs physicists Robert Wilson (left) and Arno Penzias, in front of the antenna that first detected the cosmic background radiation.

environment today. Almost all research laboratories are supported by companies that have to show profit. If you look back to the 1970s, there were a lot of industrial research laboratories: General Motors had a lab, General Electric had one. At some point these companies began to realize that these laboratories weren't giving them any competitive advantage. The leaders of AT\&T realized that basic research at Bell Labs is fun, and interesting things come out of it, but questioned whether the Bell System profited from it.

\section{Pressure to publish is felt keenly by} researchers, especially at the start of their career. What publishing strategies would you recommend to aspiring scientists? It's tricky; the 'publish or perish' attitude might encourage people to publish things that aren't very exciting, or to put a little spin on it, so that's something to be careful about. Some people don't want to publish something that they don't completely understand, but that can be very limiting. For one thing, you won't publish much. Plus, there is a tremendous value to getting your results out to the scientific community, both so that your work can be evaluated but also so that someone else can look at your results and potentially spot something important that you've missed. It is important that results be shared.

\section{If you could give your pre-university self one} piece of advice, what would it be?

The same advice that I give my undergrad students at Stanford. You need to understand what your motivation is, who you are, what you enjoy doing, and what you're good at. If you optimize all those things, you will be a good scientist.

Have you forgiven the Nobel committee for waking you up at 2:30 in the morning? [Laughter] It's really interesting. There have been times when I thought maybe my life would be richer and fuller if I had not got the Nobel prize. But you end up doing different things. One has to be careful though. There are a lot of organizations that particularly love having Nobel laureates on their advisory boards, not because the laureates are going to give good advice, but because it looks nice to have them on your advisory board. I am now at a point where I'm pretty good at saying no to this sort of thing.

There are exciting things that people invite you to do, mostly because you have the Nobel. These opportunities have distracted me from what I used to do; ironically the Nobel prize resulted in my doing less science!

Some people are able to put all of this stuff behind them and continue researching. In particular, in high-energy physics, where there's a lot of money involved, researchers can use the Nobel prize as a lever to get resources to do experiments that they couldn't do otherwise.

But it's a fascinating life. I visit all sorts of different places. I give talks that have important messages in them, and I hope that some people recognize the importance of the strategies I describe. I will continue doing what I'm doing until I'm too old to do it.

Interview by Dan Csontos, a science writer based in Lund, Sweden.

\section{\&,3 Question posed by \\ Ulrika Forsberg, a PhD candidate at Lund University in Sweden, who is studying superheavy elements.}

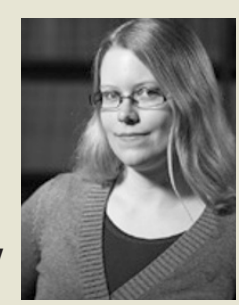

It's reassuring to know that good practices in the basics of science might actually help you do Nobel prizewinning research! But, although obvious, these things are not necessarily easy. For example, to understand what's going to work and what won't requires a thorough knowledge of the field of research and the experimental technique. This makes Osheroff's answer not so much a checklist on how to succeed, but rather hints that persistence as well as curiosity are what brings you to your goal.

$\rightarrow$ SCIENTIFICAMERICAN.COM You can visit Ulrika's 30 Under 30 page: go.nature.com/zaD4ry 